\title{
Market Behavior in the Face of Political Violence: Evidence from Tsarist Russia
}

\author{
Christopher A. Hartwell 1,2 (D) \\ 1 International Management Institute, Department of International Business, ZHAW School of Management \\ and Law, 8400 Winterthur, Switzerland; Christopher.Hartwell@zhaw.ch or chartwell@kozminski.edu.pl \\ 2 Department of International Management, Kozminski University, 03-301 Warsaw, Poland
}

check for updates

Citation: Hartwell, Christopher A. 2021. Market Behavior in the Face of Political Violence: Evidence from Tsarist Russia. Journal of Risk and Financial Management 14: 445. https://doi.org/10.3390/ jrfm14090445

Academic Editor: Vanja Piljak

Received: 26 August 2021

Accepted: 11 September 2021

Published: 15 September 2021

Publisher's Note: MDPI stays neutral with regard to jurisdictional claims in published maps and institutional affiliations.

Copyright: (C) 2021 by the author. Licensee MDPI, Basel, Switzerland. This article is an open access article distributed under the terms and conditions of the Creative Commons Attribution (CC BY) license (https:// creativecommons.org/licenses/by/ $4.0 /)$.

\begin{abstract}
Even efficient financial markets may break down under periods of prolonged stress, especially when the ramification of an event is unclear. Political violence is such an event, sending immediate signals about possible impact on firm valuations but unclear information about the future viability of existing institutions. This paper examines the effect of political violence in 19th century Russia on its stock market; using a battery of unit root and variance ratio tests, the evidence is that Russian financial markets were mostly efficient in processing short-term information from political violence. However, when violence was at its peak between the assassination of the Tsar in 1881 and the 1905 revolution, large deviations from efficiency can be detected, as markets were unsure about the viability of the existing rules of the game.
\end{abstract}

Keywords: political violence; efficient markets; institutions

JEL Classification: G14; N23; D74; P48

\section{Introduction}

Financial markets have been shown to recognize the "black swan" nature of political violence, especially terrorism, and discount their occurrence appropriately (Mnasri and Nechi 2016). Indeed, effective and efficient financial markets could absorb the information contained in political instability quickly and, in the best-case scenario, could actually act as providers of information to other institutional actors on these ramifications (Bond et al. 2012).

However, even the most efficient markets can be stressed and in times of crises, interruptions to efficiency may occur (Anagnostidis et al. 2016; Aktan et al. 2019), especially in an environment where the informational content of an event is uncertain. Political violence represents such a form of stress on financial markets, as these events often do not offer precise and actionable information about the longer-term ramifications of instability. While financial markets may be incredibly efficient in the short-term in absorbing the information provided by political violence, they can remain uncertain about its future effects and prone to mispricing or distortions if the ramifications cannot be adequately ascertained. Additionally, the cumulative effect of additional instability may call into question the health of the entire institutional system of a country, with withdrawal or reallocation of portfolios a rational response to perceived continued instability.

This paper examines this question in the context of 19th century Russia, which offers an environment of repeated stress to test just what effect political volatility had on financial markets. Tsarist Russia had strong financial institutions (Ukhov 2003) but weak political institutions, with little political development or participation beyond the Tsar and his family. This reality led to sustained political violence from 1866 onward, including the assassination of the Tsar in 1881, rising to a crescendo before and after the revolution of 1905: estimates of the number killed in political violence in the first decade of the 20th century run into the tens of thousands (Geifman 1995). Using monthly data from the 
St. Petersburg Stock Exchange juxtaposed with a unique database on political violence (Hartwell 2020), this paper explores the efficiency of Russian equity markets under this form of stress. The results show that Russian markets performed efficiently in the face of most political violence, in line with and not dissimilar from modern capital markets (Goel et al. 2017). However, in the decades of highest violence and particularly in the years surrounding the 1905 Revolution, the market showed signs of stress, as the outcome of the violence was anything but clear.

\section{Methodology}

With a dearth of information available on market conditions beyond returns in Tsarist Russia, it is difficult to test for all impediments to market efficiency that may have been present surrounding the St. Petersburg Stock Exchange, such as capacity constraints or operational inefficiencies (Karolyi 2015). At the same time, a lack of digital resources for daily data during the Tsarist era means that other direct tests, such as event studies, which could uncover abnormal returns and/or behavior, are much more difficult to undertake. However, it is possible to observe overall market behavior using an index series, as the presence of a unit root implies that a time series is either a random walk or a random walk with drift (as shown in Lee et al. (2010) and Lim and Brooks (2011)). As a corollary to this assumption, returns series from an index should result in stationarity, implying efficiency (but not necessarily forming a necessary or sufficient condition to definitively state if a market is efficient, see Campbell et al. (1997)). Indeed, the presence of stationarity in a returns series may not conclusively prove market "efficiency", in the sense of market rationality; however, the presence of mean reversion or dependence does suggest that markets are mispricing capital or risk, with temporary shocks to returns overwhelming longer-term price discovery mechanisms (Worthington and Higgs 2009).

This approach to understanding market behavior may be preferable to examining abnormal returns over a longer period, as abnormal returns imply that there is a "normal" expected rate of return - a difficult exercise when examining 50 years of data, widely varying rates of the time value of money and rapid changes in the structure and development of a country's economy. Thus, the agnostic approach of unit root testing may capture mean reversion, based on the path of the data rather than an arbitrary expected return.

Market index information from the St. Petersburg Stock Exchange (SPSE) is available on monthly basis back to 1865, obtained from Goetzmann and Huang (2018). As is standard in the financial literature, broad market index returns are taken as a proxy for financial responses, with monthly returns calculated here as:

$$
R_{t}=\log \left(\frac{P_{t}}{P_{t-1}}\right)
$$

The path of both the index and the returns series is shown in Figure 1.

To test the Russian market's behavior over this 50-year period, a series of (linear) standard unit root tests may be used, namely Augmented Dickey-Fuller (ADF), Phillips-Perron (PP), Elliot-Rothenberg-Stock (ERS) and Kwiatkowski-Phillips-Schmidt-Shin (KPSS). Additionally, given research which shows that series which have a structural break may lead to under-rejection of the null hypothesis of a unit root (see Lim and Brooks 2011), unit root tests allowing for structural breaks in both additive and innovation outliers are utilized (along the lines of Zivot and Andrews (2002) and Perron (2006)). Such a break can be seen in Figure 1 occurring at the beginning of the 20th century, as the Russian stock market underwent a financial crisis starting in March 1899, bottoming out in January 1901 and, thus, these additional unit root tests are crucial to capture this regime shift. 


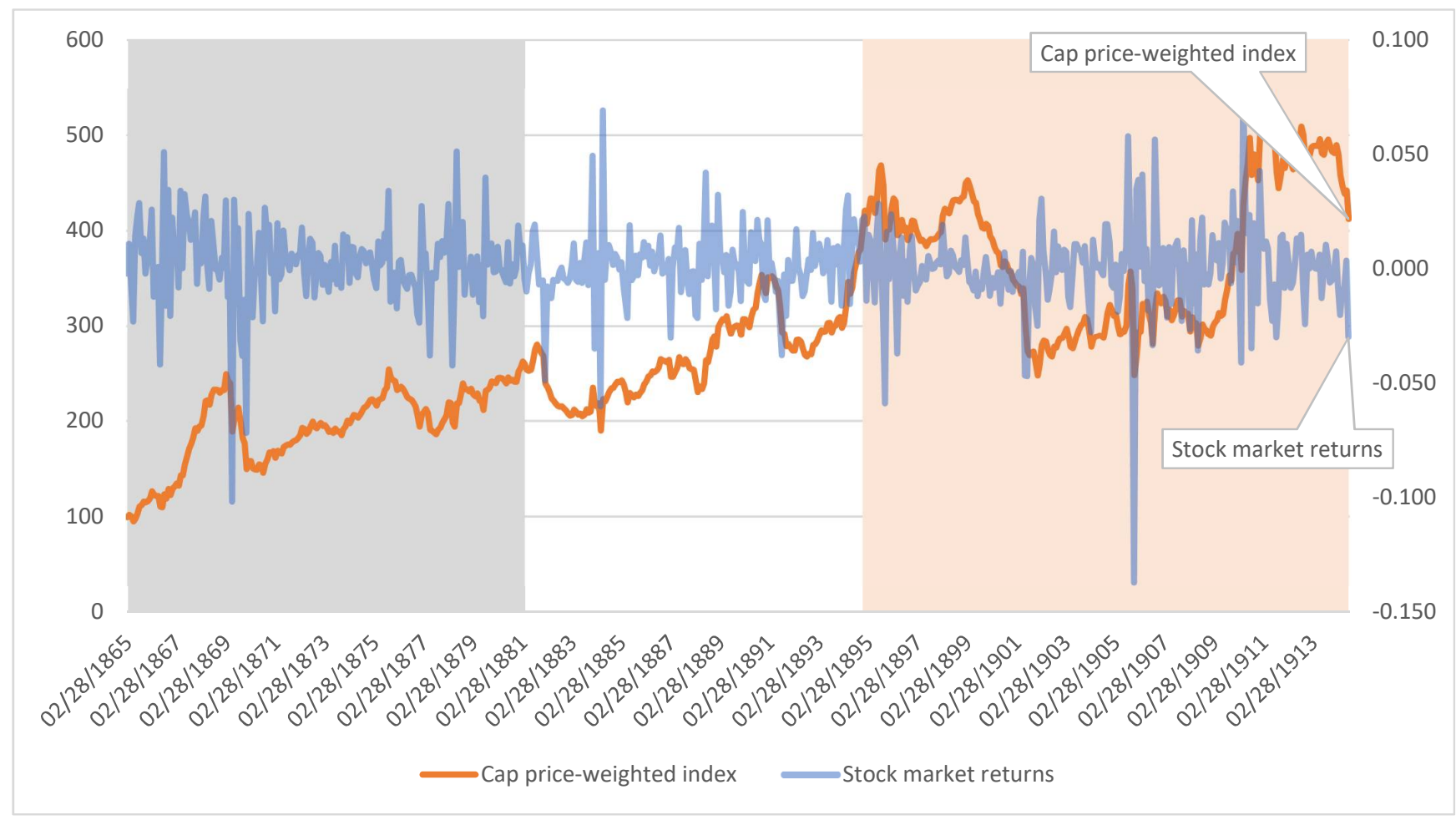

Figure 1. Monthly Log Returns in the St. Petersburg Stock Exchange versus the Index Data. Source: Author's calculations from Goetzmann and Huang (2018) data. Shaded areas indicate reign by Tsar: Alexander II (1865-1881), Alexander III (1881-1894) and Nicholas II (1894-1914).

Linear unit root tests are only a first approximation for understanding mean reversion behavior, however, and additional tests prevalent in the finance literature are also used here to explore how Russian financial markets behaved in the face of political violence. In particular, variance ratio (VR) tests are popular for examining market efficiency, generating a ratio of stock price change variance across time periods which should be equal to 1 in the presence of a random walk:

$$
\operatorname{VR}(q)=\frac{\left(\frac{1}{q}\right) \operatorname{Var}\left(p_{t}-p_{t-q}\right)}{\operatorname{Var}\left(p_{t}-P_{t-1}\right)}=\frac{\delta^{2}(q)}{\delta^{2}(1)}=1+2 \sum_{k=1}^{q-1}\left(1-\frac{k}{q}\right) \hat{\rho}(k)
$$

where the variance ratio (VR) is measured as the ratio of the variance $(\delta)$ of the $q$-th period versus the variance in period 1 , also shown as a function of an autocorrelation function $(\hat{\rho})$ of lag $k$. This individual VR test is used to compare two periods and is due to Lo and MacKinlay (1989), who also provide a test statistic to measure how significant the distance of a calculated VR of a series is from 1 based on either an assumption of homoskedasticity (test statistic $Z_{1}$ ) or heteroskedasticity (test statistic $Z_{2}$ ) $i$ the series (significance equating to correlation of prices with previous periods). A similar, but more powerful, test based on the Lo and MacKinlay approach comes from Chow and Denning (1993) who allow for multiple VR tests across time and generates a test statistic which controls for the multiple periods; as with Lo and MacKinlay, a significant test statistic implies non-efficiency. ${ }^{1}$ For this examination, we utilize Lo and MacKinlay VR test assuming heteroskedasticity, the Chow-Denning joint test and the approach of Kim (2006), which utilizes a wild bootstrap to improve the small sample properties of both tests.

Finally, and most importantly, even if an entire series linearly can be described as nonstationary, there may be periods of stationarity because of non-linearity. This reality can be captured using nonlinear unit root tests such as those designed by Kapetanios et al. (2003, hereafter KSS) and Kapetanios and Shin (2008, hereafter KS), which test a null hypothesis 
of a unit root against the alternative of a globally stationary exponential smooth transition autoregressive (ESTAR) process. The KSS approach models the market index as

$$
\Delta y_{t}=\gamma y_{t-1}\left\{1-\exp \left(-\theta y_{t-1}^{2}\right)\right\}+\varepsilon_{t}
$$

where $y$ is the demeaned or detrended time series of the index, $\gamma$ is an unknown parameter which is modeled as a first-order Taylor series approximation of $\theta$ and the error term is stochastic and assumed to have zero mean, constant variance and be normally distributed. The middle term in Equation (3) is an exponential transition function included to capture the nonlinearities of the data. The KSS approach demeans or de-trends the data using an OLS-based procedure, while the innovation of the KS approach is to instead use a GLS de-trending (de-meaning) procedure.

As shown in Aktan et al. (2019, p. 991), the presence of ESTAR stationarity indicates that markets-and especially emerging markets-have "market frictions and transaction costs ... provid[ing] grounds for arbitrage opportunities." Thus, while there may be overall efficiency, in the presence of crises or other stresses on the system (as Aktan et al. (2019) make clear), there may be episodes where uncertainty prevails, and mispricing can occur. This is a key point when understanding the effects of political violence in a weaker institutional system, where the informational content of terrorism or political violence is not evident; that is, political violence and the uncertainty it causes can stress even the most efficient of markets, but in an environment without strong supporting institutions and where the overall political environment is fragile, the effects on market behavior may be amplified.

\section{Results}

As described above, a weak-form efficient market will have non-stationarity in its levels but returns should be stationary. This effect is precisely what is shown in the results as displayed in Tables 1 and 2, as there is a clear indication of a unit root in the stock market levels but stationarity in returns. Across the ADF, PP and ERS tests (Table 1), including both drift and intercept, intercept alone and with no drift, the null of non-stationarity cannot be rejected for the index levels, while the null is rejected soundly for returns. ${ }^{2}$ Similarly, in the KPSS test, which has a null of stationarity, the results are reversed, with the index series rejecting the null and returns not rejecting the null. In any event, all of these tests point to a non-stationary index series and a stationary returns series, making the St. Petersburg Stock Exchange both I(1) and, in some sense, weak form efficient in processing information. These results hold in Table 2, where we correct for the structural breaks in the series (which the tests confirm occur sometime around 1900, as seen in Figure 1). No matter which outlier is tested for (additive or innovation), the null of a unit root cannot be rejected for the index series but is definitively rejected for the stock market returns.

Table 1. Unit root tests on stock index levels and returns.

\begin{tabular}{|c|c|c|c|c|c|c|c|c|}
\hline Test & \multicolumn{2}{|c|}{ ADF } & \multicolumn{2}{|c|}{$\mathbf{P P}$} & \multicolumn{2}{|c|}{ ERS } & \multicolumn{2}{|c|}{ KPSS } \\
\hline \multirow{2}{*}{$\begin{array}{c}\text { Null } \\
\text { Hypothesis }\end{array}$} & \multicolumn{2}{|c|}{ H0: Non-Stationary } & \multicolumn{2}{|c|}{ H0: Non-Stationary } & \multicolumn{2}{|c|}{ H0: Non-Stationary } & \multicolumn{2}{|c|}{ H0: Stationary } \\
\hline & Intercept & $\begin{array}{l}\text { Trend and } \\
\text { Intercept }\end{array}$ & Intercept & $\begin{array}{l}\text { Trend and } \\
\text { Intercept }\end{array}$ & Intercept & $\begin{array}{l}\text { Trend and } \\
\text { Intercept }\end{array}$ & Intercept & $\begin{array}{c}\text { Trend and } \\
\text { Intercept }\end{array}$ \\
\hline Index series & -1.342 & -2.466 & -1.331 & -2.470 & 47.123 & 9.374 & 2.405 & 0.244 \\
\hline$p$-values & 0.611 & 0.345 & 0.616 & 0.354 & 1.000 & 0.500 & $0.000^{* * *}$ & $0.000^{* * *}$ \\
\hline Returns & -22.110 & -22.090 & -22.070 & -22.050 & 0.108 & 0.356 & 0.059 & 0.059 \\
\hline$p$-values & $0.000^{* * *}$ & $0.000^{* * *}$ & $0.000^{* * *}$ & $0.000^{* * *}$ & $0.000^{* * *}$ & $0.000^{* * *}$ & 0.137 & 0.813 \\
\hline
\end{tabular}

Note: ADF is the Augmented Dickey-Fuller test, PP is the Phillips-Peron test, ERS is the Elliot-Rothenberg-Stock Point Optimal test and KPSS is the Kwiatkowski-Phillips-Schmidt-Shin test. ${ }^{* * *}{ }^{* *}$ and ${ }^{*}$ for $p$-values denote significance at the $1 \%, 5 \%$ and $10 \%$ levels, respectively. Sample period is for the entire sample, January 1865-July 1914. 
Table 2. Unit root tests on stock index levels and returns including structural breaks.

\begin{tabular}{|c|c|c|c|c|}
\hline & Variable & $\begin{array}{c}\text { Trend and } \\
\text { Intercept/Trend }\end{array}$ & $\begin{array}{c}\text { Trend and } \\
\text { Intercept/Intercept }\end{array}$ & $\begin{array}{l}\text { Trend Intercept/Trend } \\
\text { and Intercept }\end{array}$ \\
\hline Innovation Outlier & \multirow{2}{*}{ Index Series } & -2.7573 & -4.097 & -4.14 \\
\hline$p$-values & & 0.8206 & 0.3143 & 0.4322 \\
\hline Innovation Outlier & \multirow{2}{*}{ Returns } & -22.28 & -24.41 & -24.34 \\
\hline$p$-values & & $0.000^{* * *}$ & $0.000^{* * *}$ & $0.000^{* * *}$ \\
\hline Additive Outlier & \multirow{2}{*}{ Index Series } & -2.88 & -4.44 & -4.15 \\
\hline$p$-values & & 0.6588 & 0.1528 & 0.423 \\
\hline Additive Outlier & \multirow{2}{*}{ Returns } & -22.39 & -24.46 & -24.32 \\
\hline$p$-values & & $0.000^{* * *}$ & $0.000^{* * *}$ & $0.000^{* * *}$ \\
\hline
\end{tabular}

***,** and ${ }^{*}$ for $p$-values denote significance at the $1 \%, 5 \%$ and $10 \%$ levels, respectively. Sample period is for the entire sample, January 1865-July 1914.

Going deeper into possible measures of market behavior, the variance ratio tests noted above have the opposite null from the majority of the unit root tests, with the null hypothesis that the index series is a martingale (i.e., that it displays some attributes of weak form efficiency). As the results in Table 3 show across all of the VR tests, the null cannot be rejected for both the Lo and MacKinley individual tests and the Chow-Denning test. This result holds under the Kim (2006) wild bootstrap, as coefficients and $p$-values all are comfortably distant from rejecting the null of a martingale.

Table 3. Variance ratio tests on stock index level.

\begin{tabular}{cccc}
\hline \multicolumn{5}{c}{ H0: Index Is a Martingale } \\
\hline Individual (Lo and MacKinlay) & $\mathbf{V}(\mathbf{k})$ & Z-Statistic & p-Value \\
\hline \multicolumn{4}{c}{ Asymptotic normal } \\
\hline 2 & 1.067 & 0.794608 & 0.4268 \\
\hline 4 & 0.978 & -0.147202 & 0.883 \\
\hline 8 & 0.881 & -0.5078 & 0.6116 \\
\hline 16 & 1.130 & 0.39277 & 0.6945 \\
\hline 2 & Wild Bootstrap (Kim 2006) & 0.440 \\
\hline 4 & 1.067 & 0.795 & 0.885 \\
\hline 8 & 0.978 & -0.147 & 0.642 \\
\hline 16 & 0.881 & -0.508 & 0.688 \\
\hline Joint (Chow and Denning) & 1.130 & 0.393 & $p$-value \\
\hline Asymptotic normal & Max V(k) & Max z-statistic & 0.8291 \\
\hline Wild Bootstrap (Kim 2006) & 1.07 & 0.794608 & 0.744 \\
\hline
\end{tabular}

Tests run at periods 2: 4, 8 and 16 individually and then jointly for the Chow and Denning Test. Wild bootstrap with 1000 repetitions, two-point distribution and Knuth random generator.

However, while markets may be efficient overall, they can be prone to specific episodes of inefficiency when under stress (Aktan et al. 2019), a key issue for a country undergoing paroxysms of violence and political unrest. The results of the KSS and KS tests are shown in Table 4 and lend credibility to this interpretation: in three out of the four specifications noted, the null of a unit root is rejected in favor of a stationary ESTAR, meaning that the whole market returns were mean-reverting and not actually a random walk. Thus, while linear and less powerful non-linear tests suggest that the Russian stock market in the 19th century was efficient, the KSS and KS tests appear to suggest otherwise. 
Table 4. Non-linear unit root tests on stock index levels.

\begin{tabular}{|c|c|c|c|}
\hline \multicolumn{4}{|c|}{ Kapetanios et al. (2003)-OLS } \\
\hline \multicolumn{4}{|c|}{ de-meaned } \\
\hline Criteria & Lags & KSS stat. & $p$-Value \\
\hline FIXED & 18 & -2.525 & 0.031 ** \\
\hline AIC & 14 & -2.532 & $0.044^{* *}$ \\
\hline SIC & 0 & -2.126 & 0.141 \\
\hline GTS05 & 13 & -2.476 & $0.09 *$ \\
\hline GTS10 & 14 & -2.532 & 0.061 * \\
\hline \multicolumn{4}{|c|}{ de-trended } \\
\hline Criteria & Lags & KSS stat. & $p$-Value \\
\hline FIXED & 18 & -4.47 & $0.000 * * *$ \\
\hline AIC & 14 & -4.499 & $0.000 * * *$ \\
\hline SIC & 0 & -3.961 & $0.000^{* * *}$ \\
\hline GTS05 & 13 & -4.587 & $0.000^{* * *}$ \\
\hline GTS10 & 14 & -4.499 & $0.000 * * *$ \\
\hline \multicolumn{4}{|c|}{ Kapetanios and Shin (2008)-GLS } \\
\hline \multicolumn{4}{|c|}{ de-meaned } \\
\hline Criteria & Lags & KS stat. & $p$-Value \\
\hline FIXED & 18 & -0.326 & 0.632 \\
\hline AIC & 14 & -0.348 & 0.694 \\
\hline SIC & 0 & 0.14 & 0.832 \\
\hline GTS05 & 13 & -0.475 & 0.699 \\
\hline GTS10 & 14 & -0.348 & 0.723 \\
\hline \multicolumn{4}{|c|}{ de-trended } \\
\hline Criteria & Lags & KS stat. & $p$-Value \\
\hline FIXED & 18 & -3.325 & $0.002 * * *$ \\
\hline AIC & 14 & -3.339 & $0.004^{* * *}$ \\
\hline SIC & 0 & -2.741 & $0.022 * * *$ \\
\hline GTS05 & 11 & -3.798 & $0.001^{* * *}$ \\
\hline GTS10 & 13 & -3.551 & $0.002^{* * *}$ \\
\hline
\end{tabular}

Note: $p$-values for tests shown under the null of a unit root and the alternative of a stationary nonlinear ESTAR model. ***,** and * for $p$-values denote significance at the $1 \%, 5 \%$ and $10 \%$ levels, respectively. Fixed: fixed lag length chosen by Schwert (1989) maximum. AIC = Akaike Information Criterion. SIC: Schwarz Information Criterion. GTS05 and GTS10: General to specific algorithm with significance level set at $5 \%$ or $10 \%$, respectively. See Otero and Smith (2017). Sample period is for the entire sample, January 1865-July 1914.

It is when we unpack this result to see its driver that we can understand the effects of political violence, as Table 5 shows the results of KS and KSS tests applied to each decade of returns in Tsarist Russia. The key takeaway here is that the inefficiencies occur within the decade of 1890 to 1899 , i.e., the decade where political violence began to erupt (Figure 2) and where pre-existing financial stresses were also accumulating. During 1890 to 1899 , the KS and KSS tests show highly significant deviations from a random walk, coinciding with the surge in violence from 1890 to 1894 (see Hartwell 2020) and continuing from the unrest started by the assassination of the Tsar in 1881 . This period also contains the beginning of the financial crisis in Russia which erupted in 1899, but the fact that the bulk of the crisis 
impacted the economy only in the early 20th century perhaps discounts the crisis as an explanator for the behavior of markets in this decade.

Table 5. Non-linear unit root tests by decade on stock index levels.

\begin{tabular}{|c|c|c|c|c|c|c|}
\hline & \multicolumn{3}{|c|}{ Kapetanios et al. (2003) } & \multicolumn{3}{|c|}{ Kapetanios and Shin (2008) } \\
\hline \multicolumn{7}{|c|}{$1866-1869$} \\
\hline \multicolumn{7}{|c|}{ de-trended } \\
\hline Criteria & Lags & KSS stat. & $p$-Value & Lags & KS stat. & $p$-Value \\
\hline FIXED & 9 & -0.107 & 0.976 & 9 & -1.376 & 0.662 \\
\hline AIC & 0 & 1.846 & 1.00 & 7 & -1.81 & 0.573 \\
\hline SIC & 0 & 1.846 & 1.00 & 0 & -0.02 & 0.997 \\
\hline GTS05 & 0 & 1.846 & 1.00 & 7 & -1.81 & 0.563 \\
\hline GTS10 & 7 & -0.348 & 0.971 & 7 & -1.81 & 0.571 \\
\hline \multicolumn{7}{|c|}{ 1870-1879 } \\
\hline Criteria & Lags & KSS stat. & $p$-Value & Lags & KS stat. & $p$-Value \\
\hline FIXED & 12 & -2.768 & 0.063 & 12 & -2.432 & 0.08 \\
\hline AIC & 0 & -1.901 & 0.509 & 0 & -1.665 & 0.541 \\
\hline SIC & 0 & -1.901 & 0.471 & 0 & -1.665 & 0.518 \\
\hline GTS05 & 0 & -1.901 & 0.56 & 0 & -1.665 & 0.602 \\
\hline GTS10 & 11 & -2.52 & 0.203 & 0 & -1.665 & 0.583 \\
\hline \multicolumn{7}{|c|}{ 1880-1889 } \\
\hline Criteria & Lags & KSS stat. & $p$-Value & Lags & KS stat. & $p$-Value \\
\hline FIXED & 12 & -3.121 & $0.025^{* *}$ & 12 & -2.121 & 0.162 \\
\hline AIC & 8 & -3.038 & $0.063 *$ & 8 & -2.101 & 0.275 \\
\hline SIC & 1 & -2.072 & 0.362 & 1 & -1.349 & 0.733 \\
\hline GTS05 & 3 & -2.664 & 0.162 & 1 & -1.349 & 0.784 \\
\hline GTS10 & 8 & -3.038 & $0.065 *$ & 8 & -2.101 & 0.306 \\
\hline \multicolumn{7}{|c|}{ 1890-1899 } \\
\hline Criteria & Lags & KSS stat. & $p$-Value & Lags & KS stat. & $p$-Value \\
\hline FIXED & 12 & -4.113 & $0.001^{* * *}$ & 12 & -3.835 & $0.001^{* * *}$ \\
\hline AIC & 12 & -4.113 & $0.003^{* * *}$ & 4 & -2.625 & $0.098^{*}$ \\
\hline SIC & 0 & -2.83 & $0.082 *$ & 0 & -2.717 & $0.067 *$ \\
\hline GTS05 & 11 & -3.737 & $0.01^{* * *}$ & 11 & -3.464 & $0.014^{* *}$ \\
\hline GTS10 & 12 & -4.113 & $0.003^{* * *}$ & 12 & -3.835 & $0.004^{* * *}$ \\
\hline \multicolumn{7}{|c|}{ 1900-1909 } \\
\hline Criteria & Lags & KSS stat. & $p$-Value & Lags & KS stat. & $p$-Value \\
\hline FIXED & 12 & -2.846 & $0.052 *$ & 12 & -1.49 & 0.51 \\
\hline AIC & 3 & -1.881 & 0.522 & 3 & -0.796 & 0.951 \\
\hline SIC & 0 & -2.2 & 0.291 & 0 & -1.304 & 0.76 \\
\hline GTS05 & 9 & -2.534 & 0.21 & 9 & -1.285 & 0.816 \\
\hline GTS10 & 11 & -2.828 & 0.106 & 9 & -1.285 & 0.805 \\
\hline
\end{tabular}


Table 5. Cont.

\begin{tabular}{|c|c|c|c|c|c|c|}
\hline & \multicolumn{3}{|c|}{ Kapetanios et al. (2003) } & \multicolumn{3}{|c|}{ Kapetanios and Shin (2008) } \\
\hline \multicolumn{7}{|c|}{ 1903-1905 } \\
\hline Criteria & Lags & KSS stat. & $p$-Value & Lags & KS stat. & $p$-Value \\
\hline FIXED & 9 & -1.412 & 0.60 & 9 & -1.355 & 0.655 \\
\hline AIC & 1 & -4.512 & $0.004^{* * *}$ & 1 & -4.475 & $0.004^{* * *}$ \\
\hline SIC & 1 & -4.512 & $0.003 * * *$ & 1 & -4.475 & $0.003^{* * *}$ \\
\hline GTS05 & 1 & -4.512 & $0.003^{* * *}$ & 1 & -4.475 & $0.003^{* * *}$ \\
\hline GTS10 & 6 & -2.403 & 0.271 & 6 & -2.362 & 0.283 \\
\hline \multicolumn{7}{|c|}{$1910-1914$} \\
\hline Criteria & Lags & KSS stat. & $p$-Value & Lags & KS stat. & $p$-Value \\
\hline FIXED & 8 & -0.061 & 0.924 & 8 & -0.122 & 0.952 \\
\hline AIC & 7 & -0.656 & 0.936 & 7 & -0.687 & 0.969 \\
\hline SIC & 7 & -0.656 & 0.924 & 7 & -0.687 & 0.965 \\
\hline GTS05 & 0 & -0.472 & 0.951 & 0 & -0.495 & 0.977 \\
\hline GTS10 & 7 & -0.656 & 0.916 & 7 & -0.687 & 0.954 \\
\hline
\end{tabular}

Note: $p$-values for tests shown under the null of a unit root and the alternative of a stationary nonlinear ESTAR model. ${ }^{* * *},{ }^{* *}$ and ${ }^{*}$ for $p$-values denote significance at the $1 \%, 5 \%$ and $10 \%$ levels respectively. Fixed: fixed lag length chosen by Schwert (1989) maximum. AIC = Akaike Information Criterion. SIC: Schwarz Information Criterion. GTS05 and GTS10: General to specific algorithm with significance level set at $5 \%$ or $10 \%$, respectively. See Otero and Smith (2017).

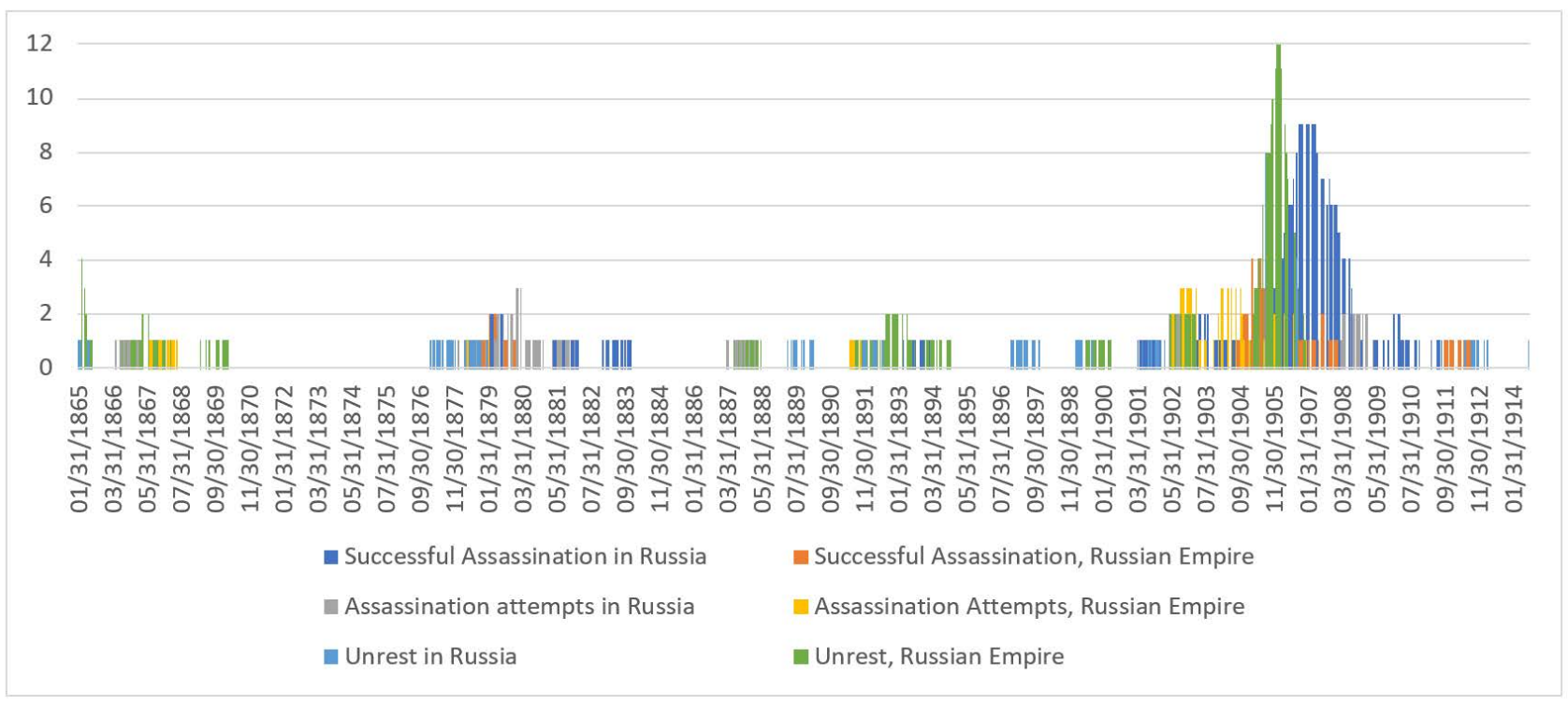

Figure 2. Months within the past year with an event of political violence. Note: Bars show the number of months in the year preceding a particular month in which at least one episode of that type of political violence occurred (meaning a minimum of 0 if no violence occurred to a maximum of 12 if at least one act occurred in each month of the preceding year). Political violence broken out by assassination attempts, successful assassinations and unrest (collective violence) in both Russia proper and in the Russian Empire only (Ukraine, the Caucasus, conquered Poland and the Baltic States). More detail available at Hartwell (2020).

Perhaps more interestingly is looking closer around the events surrounding the Revolution of 1905, where approximately 20,000 people were killed over the course of the entire year (Clodfelter 2017) and where there was little sense of the end result, how it would impact Russia's political institutions and how financial markets should react (Opitz 2018). Table 5 also shows that six out of the ten tests from mid-1903 to end-1905 (widely ac- 
knowledged as the "revolutionary surge" in Russia, see Wynn (2014)) show dependence, providing more evidence that financial markets were efficient in the face of "normal" turmoil but had difficulties coping with regime-threatening turmoil. When the end of the violence and consolidation of the monarchy came about after 1907, it can be seen that market price discovery mechanisms returned to normal functioning and were, in fact, incredibly strong during the period before the First World War (1910-1914).

An argument can be made here (in fact, should be made) that the time series for this series of tests surrounding the 1905 revolution is quite short (31 observations) and even KSS performed Monte Carlo tests at a minimum of 50 observations, noting that there is a tendency towards over-rejection of the null in small samples depending on the lag length determination procedure; as Otero and Smith (2017, p. 713) note, the "implied [critical values] decrease (in an absolute sense) in $p$ when the augmentation order is fixed by the user, while they increase (in an absolute sense) in $p_{\max }$ when it is optimally determined using any data-dependent procedures [i.e., information criterion] that are being considered." ${ }^{3}$ Ironically, despite the smaller number of observations from 1903 to 1905, the opposite actually occurs in Table 5, as it is the larger number of lags under the fixed and general to specific approach which are insignificant when, according to the exigencies of the test, these should be the ones which suffer from over-rejection of the null.

In any event, given the possible problems with such a small sample surrounding the revolution, we expand the sample in two ways. First, we will widen the net around the 1905 revolution to capture more of the violence preceding and the political uncertainty following, stretching the sample from May 1902 (when multiple assassinations by Socialist Revolutionaries occurred) to December 1907, a total of 68 observations. Secondly, we will then focus on the entire period of maximum terrorism in Russia, namely from March 1881 (the assassination of the Tsar) to December 1907 (the end of Russia's first revolution and the monarchists countercoup against the Duma). This allows us to have 322 observations, well over half our sample of 561 months and half again as many observations as utilized by Kapetanios and Shin (2008) in their examination of exchange rates. ${ }^{4}$

Results for both the OLS and GLS de-trended unit root tests for the expanded period around the October Revolution are shown in Table 6 and the results point towards confirmation of the thesis that markets were rattled by the cumulative violence. In the KSS test, there are two rejections of the null of a unit root (and the fixed lax length is tantalizingly close to the $10 \%$ significance level), while using the GLS de-trending of the KS test, we see that in three of the five criteria, inefficiencies are detected: this matches up with the results of the 1903-1905 sample, but, unlike that earlier test, significance holds across longer and shorter lag lengths. As this period excludes the financial crisis that hit Russia from 1899 to 1902 and output had already begun to grow as of 1902 (Lychakov 2019), we cannot say that it was other economic factors which generated this result, especially when one notes that Russia's main partners (the UK and France) were also growing during this time (Asselain 1984).

Finally, looking at the total period of revolutionary violence in Russia before the First World War (shown here as from 1881 to 1907, in Table 7), the results are much stronger for financial market stress. In particular, for both the KSS and KS tests (and at lag lengths of up to 16 months), four out of the five criteria confirm the effects of this stress in financial markets, while the fifth criteria in each instance (the Schwarz information criterion) chooses a much lower lag length but still comes in just above the $10 \%$ significance threshold. While this period includes the aforementioned financial crisis, the fact that the series runs for 18 years prior to the crisis and then five years post crisis argues against this being the driving factor for dependence of returns in the markets. Indeed, the sheer length of the time period and the fact that it lines up with the period of revolutionary terror in Russia provides evidence that Russia's financial markets faced difficulties in the face of sustained political violence. If anything, the financial crisis appears to have amplified the effects of pre-existing political violence rather than the other way around. 
Table 6. Non-linear unit root test on stock index levels over the pre- and post-revolutionary period.

\begin{tabular}{ccccccc}
\hline \multicolumn{7}{c}{ Kapetanios et al. (2003) } \\
\hline \multicolumn{7}{c}{ May 1902-December 1907 } \\
\hline \multicolumn{7}{c}{ de-trended } \\
\hline Criteria & Lags & KSS stat. & $p$-Value & Lags & KS stat. & $p$-Value \\
\hline FIXED & 11 & -2.53 & 0.106 & 11 & -2.75 & $0.043^{* *}$ \\
\hline AIC & 8 & -2.162 & 0.356 & 10 & -2.706 & 0.105 \\
\hline SIC & 1 & -4.386 & $0.001^{* * *}$ & 1 & -4.366 & $0.001^{* * *}$ \\
\hline GTS05 & 1 & -4.386 & $0.002^{* * *}$ & 1 & -4.366 & $0.001^{* * *}$ \\
\hline GTS10 & 10 & -2.499 & 0.215 & 10 & -2.706 & 0.109
\end{tabular}

Note: $p$-values for tests shown under the null of a unit root and the alternative of a stationary nonlinear ESTAR model. ${ }^{* * *}, * *$ and ${ }^{*}$ for $p$-values denote significance at the $1 \%, 5 \%$ and $10 \%$ levels respectively. Fixed: fixed lag length chosen by Schwert (1989) maximum. AIC = Akaike Information Criterion. SIC: Schwarz Information Criterion. GTS05 and GTS10: General to specific algorithm with significance level set at $5 \%$ or $10 \%$ respectively. See Otero and Smith (2017).

Table 7. Non-linear unit root test on stock index levels over the period of violence.

\begin{tabular}{|c|c|c|c|c|c|c|}
\hline & \multicolumn{3}{|c|}{ Kapetanios et al. (2003) } & \multicolumn{3}{|c|}{ Kapetanios and Shin (2008) } \\
\hline \multicolumn{7}{|c|}{ 1881-1907 } \\
\hline \multicolumn{7}{|c|}{ de-trended } \\
\hline Criteria & Lags & KSS stat. & $p$-Value & Lags & KS stat. & $p$-Value \\
\hline FIXED & 16 & -3.283 & $0.006^{* * *}$ & 16 & -2.894 & $0.01^{* * *}$ \\
\hline AIC & 11 & -3.409 & $0.008^{* * *}$ & 11 & -3.038 & $0.013^{* *}$ \\
\hline SIC & 3 & -2.388 & 0.127 & 3 & -2.11 & 0.121 \\
\hline GTS05 & 11 & -3.409 & $0.011^{* *}$ & 11 & -3.038 & $0.019^{* *}$ \\
\hline GTS10 & 11 & -3.409 & $0.009^{* * *}$ & 11 & -3.038 & $0.014^{* *}$ \\
\hline
\end{tabular}

Note: $p$-values for tests shown under the null of a unit root and the alternative of a stationary nonlinear ESTAR model. ${ }^{* * *},{ }^{* *}$ and $*$ for $p$-values denote significance at the $1 \%, 5 \%$ and $10 \%$ levels respectively. Fixed: fixed lag length chosen by Schwert (1989) maximum. AIC = Akaike Information Criterion. SIC: Schwarz Information Criterion. GTS05 and GTS10: General to specific algorithm with significance level set at 5\% or $10 \%$ respectively. See Otero and Smith (2017).

\section{Conclusions}

Financial markets may be on the whole weak form efficient, but even they have their limits in the face of uncertainty, especially with the informational content of an event of political violence is unknown. This paper has shown that even normally efficient markets may have periods where even the presence of new information-encapsulated in political violence-does not aid price discovery, mainly because the informational content of the event is uncertain and can have both short- and long-term ramifications. Russia in the 19th century provided an excellent test for this thesis and the use of 50 years of monthly data allowed us to observe precisely where these pockets occurred, i.e., overlapping with intense political violence. Taken individually, each of the linear unit root and variance ratio tests provided evidence for the market efficiency of Tsarist Russia but, taken in tandem with the nonlinear tests of Kapetanios et al. (2003) and Kapetanios and Shin (2008), the picture is of a weak form efficient market which, in times of considerable stress created by political volatility, became rattled and uncertain.

The extensions to this work are many. In the first instance, the approach outlined here may be utilized for other countries with perhaps more robust market data (including on market microstructure), allowing for more direct testing of market efficiency in addition to the pervasive uncertainty accompanying political violence. This may be difficult in 19th century Russia, due to the dearth of daily data, but (possibly) could be done with 
more archival research. Other approaches, including event studies, might also home in on specific episodes of inefficiency, but these too would require more detailed daily data. Finally, we can also expand our lens beyond Tsarist Russia and to other countries with prolonged experiences with terrorism or political violence, such as Italy or West Germany in the 1970s or during the history of the conflict in Northern Ireland. Regardless, this research calls for more investigation into the longer-term effects of political instability on capital markets, a highly relevant topic in a post-COVID world.

Funding: This research received no external funding.

Data Availability Statement: The political violence data is available at https: / www.openicpsr.org/ openicpsr/project/117682/version/V1/view/. Financial market data available from the author on request.

Conflicts of Interest: The author declares no conflict of interest.

\section{Notes}

1 For an excellent tour through the mathematics of these various tests, see Hung (2009).

2 Lag length was chosen automatically by commonly used information criteria.

3 The 1890-1899 data has a time series of 120 months, closer to the Kapetanios et al. (2003) sample of 160 and far above the minimum of Kapetanios and Shin (2008) and, thus, suffers less from this issue.

4 Kapetanios and Shin (2008) fix their time series at $\mathrm{T}=200$ for this application.

\section{References}

Aktan, Ceyda, Perihan Iren, and Tolga Omay. 2019. Market development and market efficiency: Evidence based on nonlinear panel unit root tests. The European Journal of Finance 25: 979-93. [CrossRef]

Anagnostidis, Panagiotis, Christos Varsakelis, and Christos J. Emmanouilides. 2016. Has the 2008 financial crisis affected stock market efficiency? The case of Eurozone. Physica A: Statistical Mechanics and its Applications 447: 116-28. [CrossRef]

Asselain, Jean Charles. 1984. Histoire économique de la France du XVIII Siècle à nos Jours. 1. De l'ancien Régime à la Première Guerre Mondiale. Paris: Editions du Seuil.

Bond, Philip, Alex Edmans, and Itay Goldstein. 2012. The Real Effects of Financial Markets. Annual Review of Financial Economics 4: 339-60. [CrossRef]

Campbell, John Y., Andrew W. Lo, and A. Craig MacKinlay. 1997. The Econometrics of Financial Markets. Princeton: Princeton University Press.

Chow, K. Victor, and Karen C. Denning. 1993. A simple multiple variance ratio test. Journal of Econometrics 58: 385-401. [CrossRef]

Clodfelter, Micheal. 2017. Warfare and Armed Conflicts: A Statistical Encyclopedia of Casualty and Other Figures, 1492-2015. Jefferson: McFarland Books.

Geifman, Anna. 1995. Thou Shalt Kill: Revolutionary Terrorism in Russia, 1894-1917. Princeton: Princeton University Press.

Goel, Sanjay, Seth Cagle, and Hany Shawky. 2017. How vulnerable are international financial markets to terrorism? An empirical study based on terrorist incidents worldwide. Journal of Financial Stability 33: 120-32. [CrossRef]

Goetzmann, William N., and Simon Huang. 2018. Momentum in Imperial Russia. Journal of Financial Economics 130: 579-91. [CrossRef]

Hartwell, Christopher A. 2020. Shooting for the Tsars: Heterogeneous political volatility and institutional change in Russia. Terrorism and Political Violence, 1-19. [CrossRef]

Hung, Jui-Cheng. 2009. Deregulation and liberalization of the Chinese stock market and the improvement of market efficiency. The Quarterly Review of Economics and Finance 49: 843-57. [CrossRef]

Kapetanios, George, and Yongcheol Shin. 2008. GLS detrending-based unit root tests in nonlinear STAR and SETAR models. Economics Letters 100: 377-80. [CrossRef]

Kapetanios, George, Yongcheol Shin, and Andy Snell. 2003. Testing for a unit root in the nonlinear STAR framework. Journal of Econometrics 112: 359-79. [CrossRef]

Karolyi, G. Andrew. 2015. Cracking the Emerging Markets Enigma. New York: Oxford University Press.

Kim, Jae H. 2006. Wild bootstrapping variance ratio tests. Economics Letters 92: 38-43. [CrossRef]

Lee, Chien Chiang, Jun De Lee, and Chi Chuan Lee. 2010. Stock prices and the efficient market hypothesis: Evidence from a panel stationary test with structural breaks. Japan and the World Economy 22: 49-58. [CrossRef]

Lim, Kiam Ping, and Robert Brooks. 2011. The evolution of stock market efficiency over time: A survey of the empirical literature. Journal of Economic Surveys 25: 69-108. [CrossRef]

Lo, Andrew W., and A. Craig MacKinlay. 1989. The size and power of the variance ratio test in finite samples: A Monte Carlo investigation. Journal of Econometrics 40: 203-38. [CrossRef]

Lychakov, Nikita. 2019. From Financial Crisis to Revolution: Russia 1899-1905 (No. 95166). Munich: University Library of Munich. 
Mnasri, Ayman, and Salem Nechi. 2016. Impact of terrorist attacks on stock market volatility in emerging markets. Emerging Markets Review 28: 184-202. [CrossRef]

Opitz, Alexander. 2018. “Comrades, Let's March!". The Revolution of 1905 and its impact on financial markets. European Review of Economic History 22: 28-52. [CrossRef]

Otero, Jesús, and Jeremy Smith. 2017. Response surface models for OLS and GLS detrending-based unit-root tests in nonlinear ESTAR models. The Stata Journal 17: 704-22. [CrossRef]

Perron, Pierre. 2006. Dealing with structural breaks. Palgrave Handbook of Econometrics 1: 278-352.

Schwert, G. William. 1989. Tests for unit roots: A Monte Carlo investigation. Journal of Business and Economic Statistics 7: 147-60.

Ukhov, Andrey. 2003. Financial Innovation and Russian Government Debt before 1918. Working Paper No. 03-20. New Haven: Yale International Center for Finance.

Worthington, Andrew C., and Helen Higgs. 2009. Efficiency in the Australian stock market, 1875-2006: A note on extreme long-run random walk behaviour. Applied Economics Letters 16: 301-6. [CrossRef]

Wynn, Charters. 2014. Workers, Strikes, and Pogroms: The Donbass-Dnepr Bend in Late Imperial Russia, 1870-1905. Princeton: Princeton University Press.

Zivot, Eric, and Donald W. K. Andrews. 2002. Further evidence on the great crash, the oil-price shock, and the unit-root hypothesis. Journal of Business \& Economic Statistics 20: 25-44. 